\title{
Low levels of serum urate are associated with a higher prevalence of depression in older adults: a nationwide cross-sectional study in Korea
}

Woo-Joong Kim', Hye Ri Kim², Jung Soo Song ${ }^{1}$ and Sang Tae Choi ${ }^{1^{*}}$ (D)

\begin{abstract}
Background: Soluble urate has been shown to serve as an antioxidant, especially in the central nervous system. Although there are intriguing data suggesting that low levels of serum urate are associated with worse outcomes in neurodegenerative diseases, its impact on mental health has not been adequately assessed. Thus, we aimed to investigate the association between serum urate and depression using a large, nationally representative sample.

Methods: Information on participants' socio-demographic characteristics as well as physical and mental health conditions were retrieved from the Korea National Health and Nutrition Examination Survey (KNHANES) 2016 dataset. The Patient Health Questionnaire (PHQ)-9 was applied to identify depressive symptoms. Analyses were stratified by age: young adults (aged 19-39 years), middle-aged adults (aged 40-59 years), and older adults (aged 60 years and older).
\end{abstract}

Results: A total of 5332 participants were included. Serum urate concentrations were divided into sex-specific quartiles based on their distribution: $\leq 4.9(\mathrm{Q} 1), 5.0-5.7(\mathrm{Q} 2), 5.8-6.6(\mathrm{Q} 3)$, and $\geq 6.7(\mathrm{Q} 4) \mathrm{mg} / \mathrm{dL}$ in men and $\leq 3.7$ (Q1), 3.8-4.3 (Q2), 4.4-4.9 (Q3), and $\geq 5.0(\mathrm{Q} 4) \mathrm{mg} / \mathrm{dL}$ in women. There was a significant negative linear relationship between serum urate quartiles and PHQ-9 scores in older adults ( $p$ for trend $=0.020$ in men and $p$ for trend $=0.048$ in women). Compared to high levels (Q3 and Q4) of serum urate, low levels (Q1 and Q2) were significantly associated with the overall burden of depression in older women (OR 1.78, 95\% Cl 1.21, 2.61) and clinically relevant depression in older men (OR 3.35, 95\% Cl 1.16, 9.70), even after adjustment.

Conclusions: Based on the KNHANES data, low levels of serum urate are associated with a higher prevalence of depression in older adults. This may have clinical implications for mental health.

Keywords: Depression, Korea National Health and Nutrition Examination Survey (KNHANES), Patient Health Questionnaire (PHQ)-9, Urate

\footnotetext{
* Correspondence: beconst@cau.ac.kr

'Division of Rheumatology, Department of Internal Medicine, Chung-Ang University College of Medicine, 102, Heukseok-ro, Dongjak-gu, Seoul 06973, Republic of Korea

Full list of author information is available at the end of the article
}

(c) The Author(s). 2020 Open Access This article is licensed under a Creative Commons Attribution 4.0 International License, which permits use, sharing, adaptation, distribution and reproduction in any medium or format, as long as you give appropriate credit to the original author(s) and the source, provide a link to the Creative Commons licence, and indicate if changes were made. The images or other third party material in this article are included in the article's Creative Commons licence, unless indicated otherwise in a credit line to the material. If material is not included in the article's Creative Commons licence and your intended use is not permitted by statutory regulation or exceeds the permitted use, you will need to obtain permission directly from the copyright holder. To view a copy of this licence, visit http://creativecommons.org/licenses/by/4.0/ The Creative Commons Public Domain Dedication waiver (http://creativecommons.org/publicdomain/zero/1.0/) applies to the data made available in this article, unless otherwise stated in a credit line to the data. 


\section{Background}

Urate is a breakdown product of human purine metabolism which, at elevated serum concentrations, can cause gout, kidney stones, and acute kidney injury. The association of hyperuricemia with adverse health outcomessuch as metabolic syndrome, cardiovascular disease, and chronic kidney disease-has been described [1]. In general, a target serum urate concentration of no higher than $6.0 \mathrm{mg} / \mathrm{dL}$ would obtain meaningful benefit from urate-lowering therapy, while a serum urate concentration of $5.0 \mathrm{mg} / \mathrm{dL}$ has been considered the target in patients with gout exhibiting severe clinical features (polyarticular distribution, with established structural joint damage or tophi) [2]. These therapeutic targets were endorsed by multiple rheumatology societies worldwide [3-7]; however, the potential unintended consequences of therapy remain a concern. The British Society of Rheumatology advocates the possibility of adverse effects that may be associated with a very low serum urate level and the European League Against Rheumatism recommends against lowering serum urate concentrations below $3.0 \mathrm{mg} / \mathrm{dL}$ in the long-term. In contrast, other guidelines do not suggest any specific action to avoid inappropriate levels of serum urate [8].

Urate reduces the oxo-heme oxidant formed by a peroxide reaction with hemoglobin and protects erythrocytes from peroxidative damage leading to lysis [9]. It has been suggested that increased urate generation represented an evolutionary advantage towards enhanced antioxidant defenses that may have conferred a survival benefit [10]. A randomized, double-blinded, placebo-controlled study demonstrated that systemic urate infusion in healthy volunteers increased serum urate concentrations by $35 \%$ from $3.8 \mathrm{mg} / \mathrm{dL}$ to $5.2 \mathrm{mg} / \mathrm{dL}$ and was associated with a 23-139\% increase in serum antioxidant capacity, depending on the assay used [11]. These effects are reported to be important in the central nervous system, in which acute administration of urate reduces neurological injury after ischemic stroke [12, 13]. Moreover, evidence suggested that higher levels of serum urate are associated with favorable neurological outcomes in Parkinson's disease, Huntington's disease, amyotrophic lateral sclerosis, and dementia [14-17]. However, there have been conflicting reports with the risk of stroke, dementia, especially vascular or mixed dementia, and Parkinson's disease due to hyperuricemia and gout [18-20].

Over the last decade, it has been hypothesized that oxidative stress pathways might also be involved in the pathophysiological mechanism of depression [21]. It has been proposed that high levels of urate are associated with a lower risk of hospitalization due to depression and antidepressant medication use in two independent cohorts [22]. A recent meta-analysis and meta-regression provided additional evidence on this relationship, in which subjects with major depressive disorder had lower levels of serum urate than healthy controls [23]. However, no association between serum urate concentrations and behavioral and clinical characteristics was found in patients with major affective disorders [24]. As the role of serum urate is largely unclear in the development of depressive disorders, which have become a leading cause of health burden worldwide [25], this study aimed to investigate the association between serum urate concentrations and the prevalence of depression in a large, nationally representative sample drawn from the Korea National Health and Nutrition Examination Survey (KNHANES) 2016 dataset.

\section{Methods}

\section{Study population}

The KNHANES is a cross-sectional, multistage, stratified, clustered probability sample survey of Korean civilians from a non-institutionalized population, conducted every year since 1998 by the Korea Centers for Disease Control and Prevention of the Ministry of Health and Welfare, designed to monitor the nation's health and nutritional status. All consenting participants underwent a semistructured interview and physical examination in a mobile examination center with blood and urine testing by standardized procedures, followed by a household interview. Each year, the survey involves a sample of roughly 70009000 individuals who are representative of Koreans. In the present study, we examined data from the publicly available KNHANES 2016 dataset of 8150 participants, in which serum urate concentrations were measured for the first time with the Patient Health Questionnaire (PHQ)-9 included as a screening instrument for depression. Exclusion criteria included age 18 years or younger $(n=1768)$, missing PHQ-9 data $(n=621)$, missing laboratory data $(n=196)$, and estimated glomerular filtration rate (eGFR) less than $60 \mathrm{~mL} / \mathrm{min} / 1.73 \mathrm{~m}^{2}(n=233)$. The remaining 5332 subjects (2301 men and 3031 women) were eligible for the analysis (Fig. 1).

\section{Measurement of serum parameters}

Blood samples were collected the morning after overnight fasting. In the chemistry panel, using a Hitachi automatic analyzer 7600-210 (Hitachi, Japan), serum urate and creatinine concentrations were measured by the calorimetric enzymatic method and the Jaffe rateblanked and compensated method, respectively. Serum high-sensitivity C-reactive protein (CRP) concentration was measured by immunoturbidimetry using a Cobas automatic analyzer (Roche, Germany).

Since the glomerular filtration rate is usually accepted as the best overall index of kidney function, eGFR was calculated using the Chronic Kidney Disease Epidemiology Collaboration equation $\left(\mathrm{eGFR}=141 \times \min \left(\mathrm{S}_{\mathrm{Cr}} / \kappa, 1\right)^{\alpha} \times \max \right.$ $\left(\mathrm{S}_{\mathrm{Cr}} / \kappa, 1\right)^{-1.209} \times 0.993^{\mathrm{Age}} \times 1.018$ [if female] $\times 1.159$ [if 


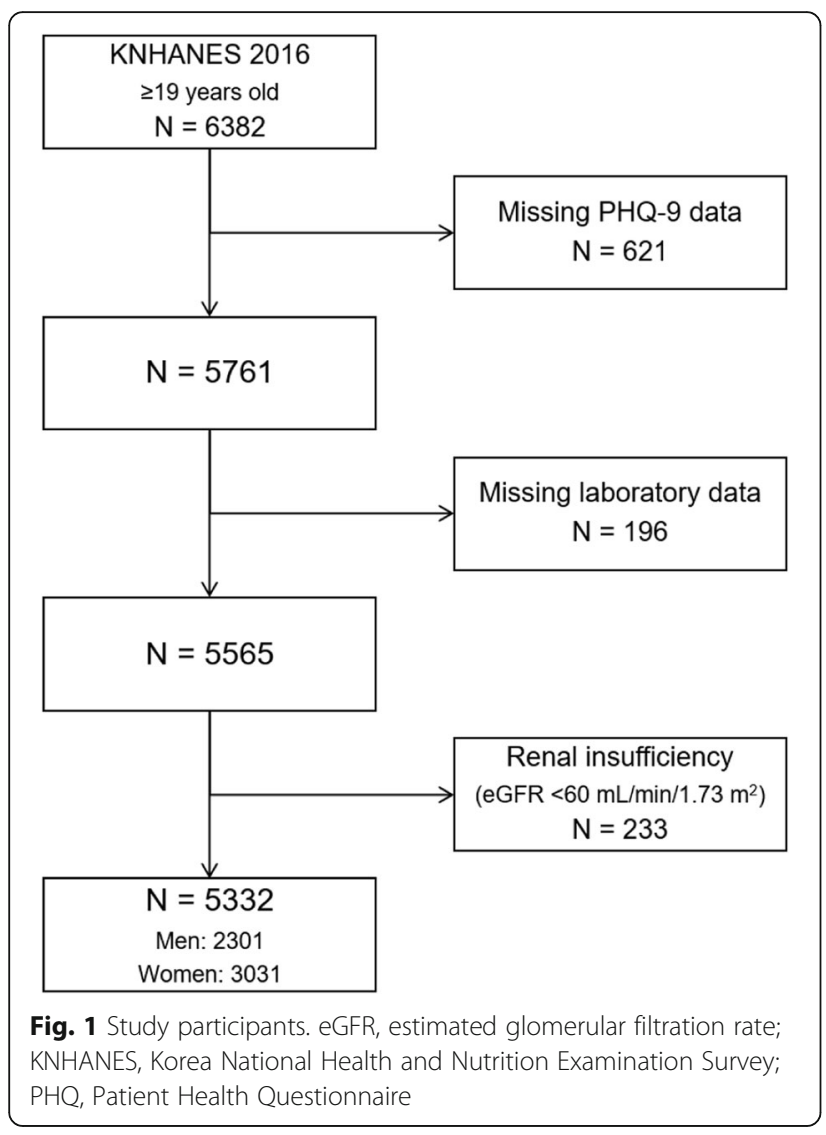

Black] $\mathrm{mL} / \mathrm{min} / 1.73 \mathrm{~m}^{2}$, where $\mathrm{S}_{\mathrm{Cr}}$ is serum creatinine, $\kappa$ is 0.7 for females and 0.9 for males, $\alpha$ is -0.329 for females and -0.411 for males, min indicates the minimum of $\mathrm{S}_{\mathrm{Cr}} / \kappa$ or 1 , and max indicates the maximum of $\mathrm{S}_{\mathrm{Cr}} / \kappa$ or 1$)$ [26].

\section{Assessment of demographic, socioeconomic, and health- related variables}

This study collected information on the participants' socio-demographic characteristics as well as physical and mental health conditions. The data were then stratified by age: young adults (aged 19-39 years), middle-aged adults (aged 40-59 years), and older adults (aged 60 years and older). Educational levels were categorized as elementary school, middle school, high school, or college, according to educational stages in Korea. Household income levels were calculated by dividing the total household monthly income by the square root of the household size; the obtained levels were then grouped into quartiles. Body mass index (BMI) was calculated as each participant's weight in kilograms divided by the square of the height in meters. We classified subjects as underweight (BMI $<18.5 \mathrm{~kg} / \mathrm{m}^{2}$ ), normal (BMI 18.5$\left.24.9 \mathrm{~kg} / \mathrm{m}^{2}\right)$, and obese (BMI $\geq 25.0 \mathrm{~kg} / \mathrm{m}^{2}$ ) according to the survey standard considering that the appropriate BMI cut-off for obesity in Asia is $25.0 \mathrm{~kg} / \mathrm{m}^{2}$ [27]. The presence of chronic disease such as hypertension, diabetes, stroke, ischemic heart disease, thyroid disease, arthritis, pulmonary tuberculosis, asthma, chronic kidney disease, liver cirrhosis, and cancer was dichotomized into yes (whether the subject had been diagnosed by a physician) or no. Lifetime diagnosis of depression (yes/no), perceived health status (very good or good/fair, poor, or very poor), and perceived stress (no or mild/much or very much) were also dichotomized. Smoking status was categorized as current smoker (an adult who has smoked 100 cigarettes in his or her lifetime and who currently smokes cigarettes) or non-smoker (an adult who has never smoked, who has smoked less than 100 cigarettes in his or her lifetime, or who had quit smoking by the time of interview). For alcohol use, drinking status was categorized as current drinker (an adult who had consumed any kind of alcoholic beverage in the past year) or non-drinker.

\section{Patient Health Questionnaire (PHQ)-9}

The PHQ-9 is a nine-item questionnaire designed to screen for depression, upon which the diagnosis of depressive disorders, as stated by the Diagnostic and Statistical Manual of Mental Disorders, Fourth Edition, is based. Participants were asked to indicate how often each depressive symptom had occurred during the preceding 2 weeks by choosing one of the following options: 0 (not at all), 1 (several days), 2 (more than half of the days), and 3 (nearly every day) [28]. The PHQ-9 has been validated to recognize not only major depression but also subthreshold depressive disorders in the general population and has been translated into several languages [29-32]. The Korean version of PHQ-9 was administered in the KNHANES with authorized permission. While a standard cut-off score of 10 has been proposed to maximize the combined sensitivity and specificity in a recent metaanalysis [33], a population-based prospective cohort study, which validated the Korean version of PHQ-9 in subjects older than 60 years, suggested that a score of 5 is the optimal cut-off for screening [34]. In this study, participants with a PHQ-9 score $\geq 5$ or self-reported current depression were included to estimate the overall burden of depressive symptoms and those with a PHQ-9 score $\geq 10$ were considered to have clinically relevant depression.

\section{Statistical analyses}

All analyses of this 1-year sample were weighted and accounted for the stratified, multistage probability sampling design of the KNHANES 2016 and survey nonresponses. Missing data were treated as valid among the strata, cluster, subpopulation, and factor variables and considered while estimating the prevalence. Descriptive statistics are presented using means or proportions with standard errors (SEs). Analysis of variance for continuous 
variables or the chi-square test for categorical variables was used to analyze the differences. The relationship between serum urate quartiles and the PHQ-9 score, as a continuous variable, was determined using the complex sample general linear models. The complex sample crosstabs procedure produced the weighted prevalence estimates for age groups to identify patterns in data. Then, the associations of serum urate quartiles with the prevalence of overall depression or clinically relevant depression, as categorical variables, were examined by the complex sample logistic regression models. Odds ratios (ORs) with 95\% confidence intervals (CIs) were calculated from the corresponding models. All statistical tests were two-tailed, and $p<0.05$ was considered significant. Data analyses were conducted using IBM SPSS Statistics for Windows, Version 23.0 (IBM Corp., Armonk, NY, USA).

\section{Results}

\section{General characteristics}

Among the 5332 subjects aged $19-80$ years enrolled in this study, the mean serum urate concentration was 5.8 $(\mathrm{SE}=0.03) \mathrm{mg} / \mathrm{dL}$ in $2301 \mathrm{men}$, which was significantly higher than the concentration of $4.3(\mathrm{SE}=0.02) \mathrm{mg} / \mathrm{dL}$ in 3031 women $(p<0.001)$. Serum urate concentrations below $3.0 \mathrm{mg} / \mathrm{dL}$ were measured in $22(0.7 \%)$ men and 181 (6.1\%) women, while only $3(0.1 \%)$ men and 10 (0.4\%) women had concentrations less than $2.0 \mathrm{mg} / \mathrm{dL}$. Serum urate concentrations were then divided into sexspecific quartiles based on their distribution: $\leq 4.9$ (Q1), 5.0-5.7 (Q2), 5.8-6.6 (Q3), and $\geq 6.7(\mathrm{Q} 4) \mathrm{mg} / \mathrm{dL}$ in men and $\leq 3.7(\mathrm{Q} 1), 3.8-4.3(\mathrm{Q} 2), 4.4-4.9(\mathrm{Q} 3)$, and $\geq$ $5.0(\mathrm{Q} 4) \mathrm{mg} / \mathrm{dL}$ in women.

Table 1 describes the general characteristics of the study population according to serum urate quartiles. A decrease in the mean age was associated with an increase in serum urate concentrations in men. An increasing trend in BMI was observed across the quartiles in both the sexes. In men, the proportions of individuals with a lifetime diagnosis of depression, self-reported current depression, and current antidepressant use were higher in the fourth quartile (Q4). The prevalence of depression (PHQ-9 score $\geq 5$ or self-reported current depression) was substantially higher among women than among men $(25.2 \%$ vs. $15.5 \%, p<0.001)$. It was also noted that clinically relevant depression (PHQ-9 score $\geq$ 10) was significantly more prevalent among women than among men $(7.0 \%$ vs. $3.9 \%, p<0.001)$. In the entire sample, there were no significant relationships between serum urate quartiles and PHQ-9 scores.

\section{Age-stratified relationships between serum urate quartiles and PHQ-9 scores}

General linear models with polynomial contrasts were used to test whether a linear trend is present between serum urate quartiles and adjusted PHQ-9 scores. Table 2 shows age-stratified relationships across the serum urate quartiles, after controlling for several sociodemographic, health-, and disease-related variables, such as age, educational levels, household income levels, categorized BMI, the presence of chronic disease, lifetime diagnosis of depression, perceived health status, perceived stress, smoking status, and drinking status. These models revealed a significant negative linear effect for adjusted PHQ-9 scores in older men ( $p$ for linear trend $=$ 0.020 ) and older women ( $p$ for linear trend $=0.048$ ). The results indicated a higher PHQ-9 score among older adults with low levels of serum urate, but this association was not valid for young or middle-aged adults.

\section{Age-stratified prevalence of depression}

Figure 2 depicts various patterns of weighted prevalence estimates for the overall depression according to serum urate quartiles. These data indicated a U-shaped trend for depression among young adults. No significant trend was detected among middle-aged adults. While the PHQ-9 scores themselves showed a linear trend that decreases with serum urate quartiles, when comparing the overall burden of depressive symptoms in older adults, a given population can be roughly divided into two equal halves. It has been demonstrated that individuals with low levels of serum urate $(\mathrm{Q} 1$ and $\mathrm{Q} 2$ rather than Q3 and Q4) have a relatively high prevalence of depression, although the difference is more pronounced in women. It was noted that the fourth quartile $(\mathrm{Q} 4)$ had a higher proportion of subjects with depression than the third quartile (Q3) in every subgroup.

Figure 3 shows a plot of weighted prevalence estimates for clinically relevant depression, which represents a more specific and serious condition, according to serum urate quartiles. In contrast to the U-shaped trend of the overall depression prevalence, an upward trend was observed among young adults of both sexes. In men, the prevalence of clinically relevant depression differed according to low levels (Q1 and Q2) and high levels (Q3 and Q4) of serum urate.

\section{Association between serum urate levels and the prevalence of depression}

Logistic regression methods were used to examine whether these differences in the prevalence of overall depression according to low and high levels of serum urate were independent of confounding variables. If the association is indeed present, the models estimated adjusted ORs in older men and women. Additionally, these analyses were repeated for clinically relevant depression in older adults.

Table 3 presents the independent associations of factors with the prevalence of overall depression. Sociodemographic, health-, and disease-related variables were 


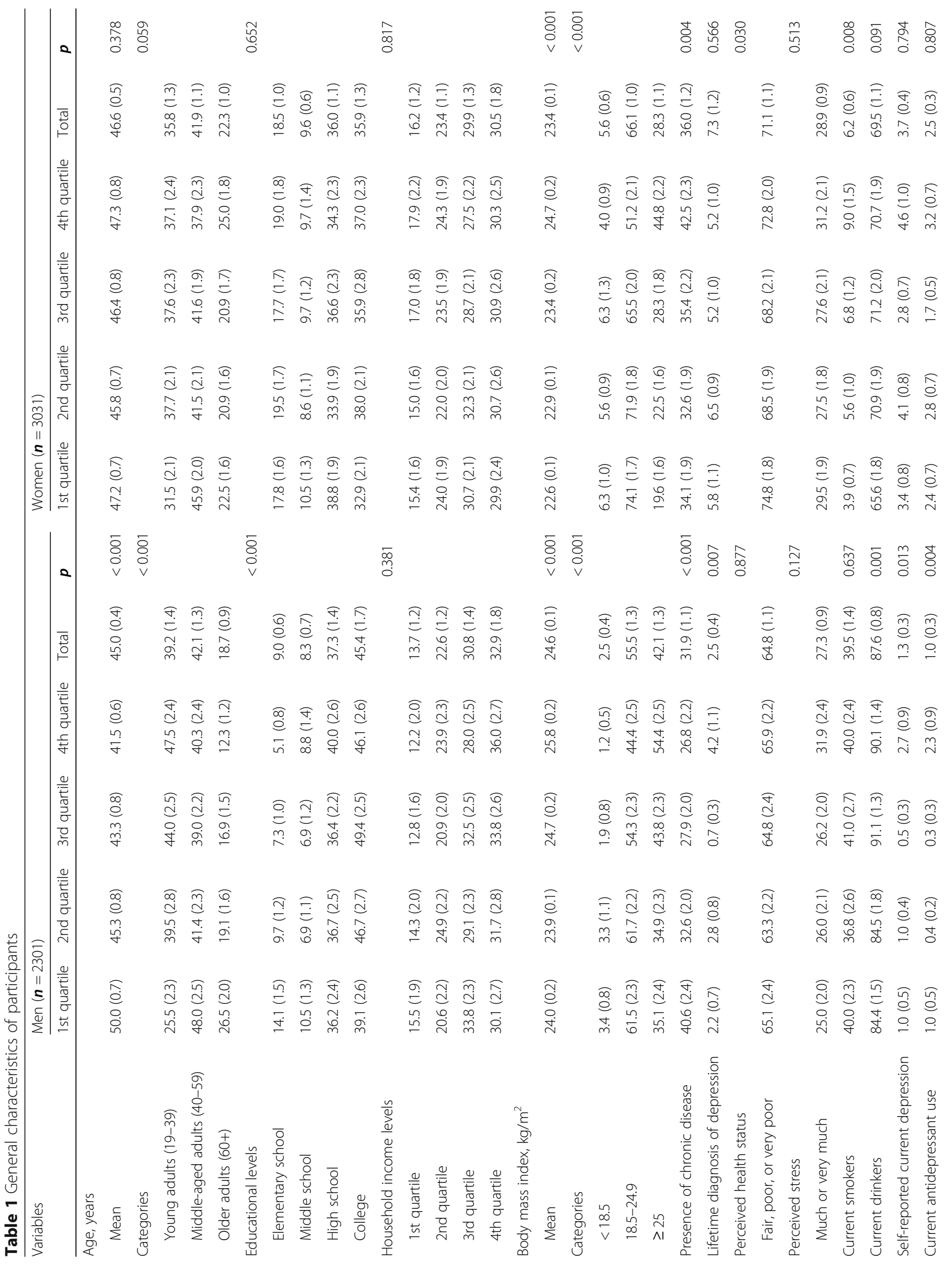




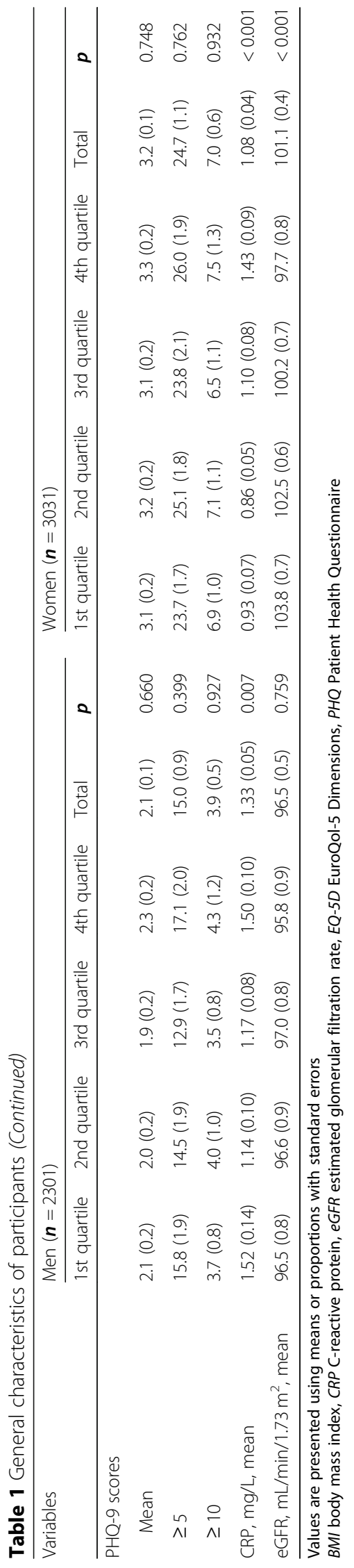


Table 2 Age-stratified relationships between serum urate quartiles and PHQ-9 scores

\begin{tabular}{|c|c|c|c|c|c|c|c|c|c|c|c|c|c|c|c|c|}
\hline & \multicolumn{4}{|c|}{$\begin{array}{l}\text { Young men (19-39 years, } n= \\
712 \text { ) }\end{array}$} & \multicolumn{4}{|c|}{$\begin{array}{l}\text { Middle-aged men ( } 40-59 \text { years, } \\
n=879)\end{array}$} & \multicolumn{4}{|c|}{$\begin{array}{l}\text { Older men ( } 60 \text { years and older, } \\
n=710)\end{array}$} & \multicolumn{4}{|c|}{ Men $(n=2301)$} \\
\hline & Mean & SE & $F$ & $p$ & Mean & SE & $F$ & $p$ & Mean & SE & $F$ & $p$ & Mean & SE & $F$ & $p$ \\
\hline 1st quartile & 6.47 & 1.33 & 0.029 & 0.865 & 3.76 & 0.44 & 0.071 & 0.790 & 4.02 & 0.54 & 5.448 & 0.020 & 4.44 & 0.46 & 0.169 & 0.681 \\
\hline 2nd quartile & 6.12 & 1.28 & & & 4.00 & 0.48 & & & 3.75 & 0.54 & & & 4.26 & 0.44 & & \\
\hline 3rd quartile & 6.37 & 1.28 & & & 3.68 & 0.45 & & & 3.65 & 0.52 & & & 4.27 & 0.43 & & \\
\hline \multirow[t]{3}{*}{ 4th quartile } & 6.45 & 1.32 & & & 3.78 & 0.52 & & & 3.23 & 0.53 & & & 4.35 & 0.46 & & \\
\hline & \multicolumn{4}{|c|}{$\begin{array}{l}\text { Young women (19-39 years, } \\
n=938)\end{array}$} & \multicolumn{4}{|c|}{$\begin{array}{l}\text { Middle-aged women (40-59 } \\
\text { years, } n=1184)\end{array}$} & \multicolumn{4}{|c|}{$\begin{array}{l}\text { Older women ( } 60 \text { years and } \\
\text { older, } n=909 \text { ) }\end{array}$} & \multicolumn{4}{|c|}{ Women $(n=3031)$} \\
\hline & Mean & SE & $F$ & $p$ & Mean & SE & $F$ & $p$ & Mean & SE & $F$ & $p$ & Mean & SE & $F$ & $p$ \\
\hline 1st quartile & 5.75 & 0.85 & 0.867 & 0.352 & 6.24 & 0.58 & 0.087 & 0.764 & 7.14 & 0.89 & 3.928 & 0.048 & 6.48 & 0.41 & 0.180 & 0.894 \\
\hline 2nd quartile & 6.43 & 0.86 & & & 6.21 & 0.56 & & & 6.78 & 0.86 & & & 6.68 & 0.39 & & \\
\hline 3rd quartile & 6.55 & 0.90 & & & 5.93 & 0.57 & & & 6.69 & 0.86 & & & 6.60 & 0.40 & & \\
\hline 4th quartile & 6.03 & 0.83 & & & 6.25 & 0.67 & & & 6.29 & 0.82 & & & 6.48 & 0.42 & & \\
\hline
\end{tabular}

$F$ and $p$ values are calculated for linear trend

PHQ Patient Health Questionnaire, SE standard error

assigned to build a statistical model. In accordance with the crude analysis, low levels (Q1 and Q2), compared to high levels (Q3 and Q4), of serum urate were identified as a significant factor for the prevalence of overall depression (OR 1.78, 95\% CI 1.21, 2.61) in older women, along with the presence of chronic disease, lifetime diagnosis of depression, poor perceived health status, and perceived stress.

The results shown in Table 4 are from the model for the prevalence of clinically relevant depression. Compared to that of high levels (Q3 and Q4), the association of low levels (Q1 and Q2) of serum urate retained significance (OR 3.35, 95\% CI 1.16, 9.70) following adjustment in men.

\section{Discussion}

To the best of our knowledge, this study is the first to highlight the association between the levels of serum urate and depression using a large, national-level database, which provided unbiased and comprehensive data of the Korean population. We demonstrated that low levels of serum urate are significantly associated with a higher PHQ-9 score and a higher prevalence of depression in older adults, even when the concentrations were within the physiological range.

Depression in older adults is associated with disability, increased mortality, and poorer outcomes of physical illness [35]; it is often inadequately treated and associated with higher relapse rates [36]. Though it is not fully understood, several etiological factors in late-life depression, especially related to aging and disease-related processes, have been shown to begin during mid-life [37], and patients with depression displayed a significantly enhanced senescent-associated secretory phenotype compared with controls [38]. Therefore, it is imperative to understand the life course perspectives on the epidemiology of depression and adhere to the United States Preventive Services Task Force's recommendation for screening for depression while calling for more research on optimal screening approaches in older adults [39].

Age-stratified analyses in our study could allow the distinction between different patterns of depression among young, middle-aged, and older adults. Given the results, the possible neuroprotective effect of urate against depressive disorders, whereby urate acts as a potent antioxidant in the extracellular environment and accounts for nearly two thirds of total serum antioxidant activity [40], may be modulated by aging, although the potential biological mechanisms underlying the observed associations are speculative. A possible rationale might be found in the meta-analysis of 48 studies involving 9203 individuals that showed an association between microvascular dysfunction and late-life depression; this can be explained, at least in part, by a high level of reactive oxygen species produced in the brain as a result of the higher metabolic demand [41]. Another study, in which plasma levels of six oxidative stress markers were measured, provided robust evidence that subjects with late-life depression exhibit a significant imbalance in the oxidative stress response [42].

Inverse associations between serum urate levels and the overall burden of depressive symptoms were significant in older women but not in older men. Although apparent differences in the prevalence of depression according to low and high levels of serum urate were shown in both sexes, a possible explanation might be that the absolute difference in our study was much smaller for men. In addition, the statistical results might be less significant because of the lower prevalence of depression in men than in women. Nonetheless, serum 

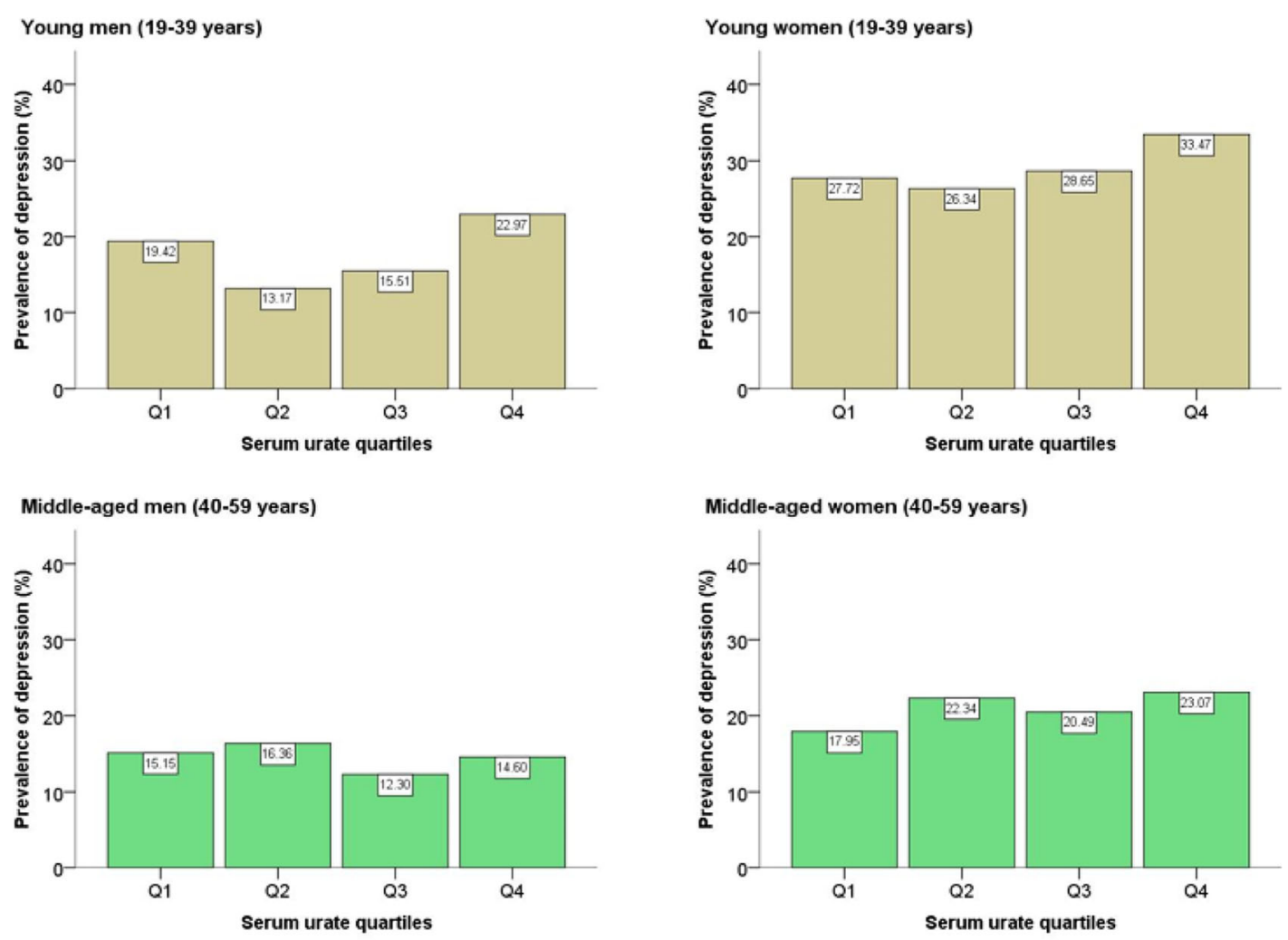

Middle-aged women (40-59 years)

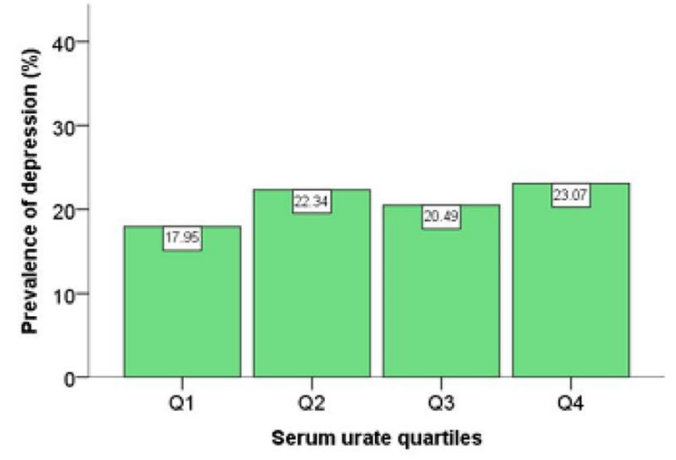

Older men (60 years and older)

Older women (60 years and older)
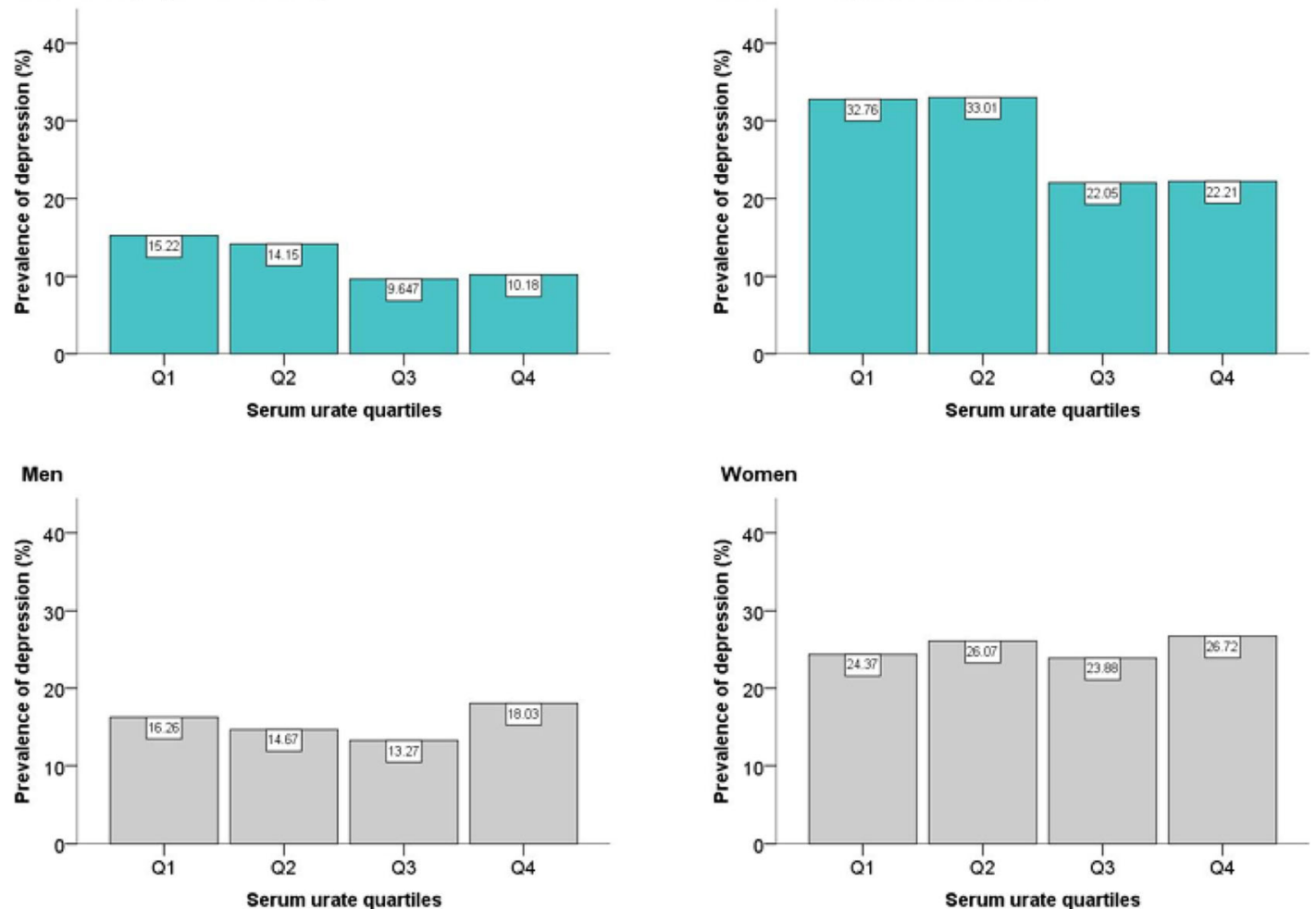

Fig. 2 Prevalence of overall depression according to serum urate quartiles 

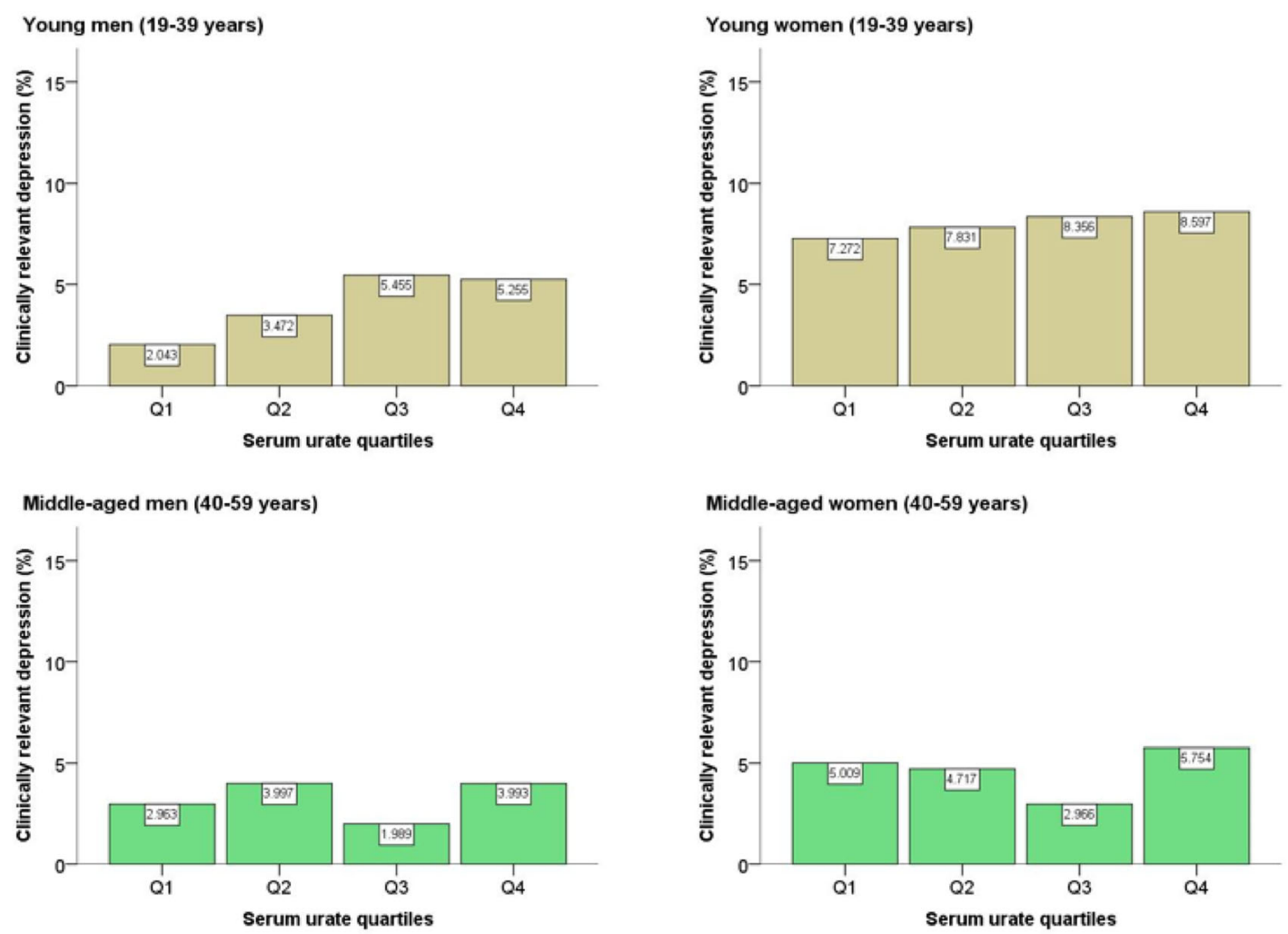

Middle-aged women (40-59 years)

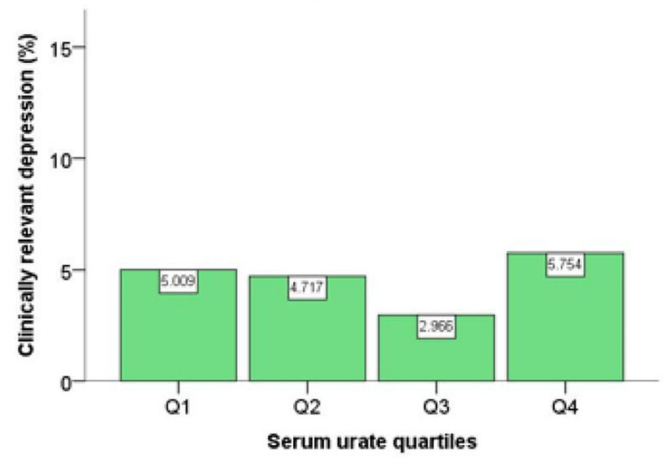

Older men (60 years and older)

Older women (60 years and older)
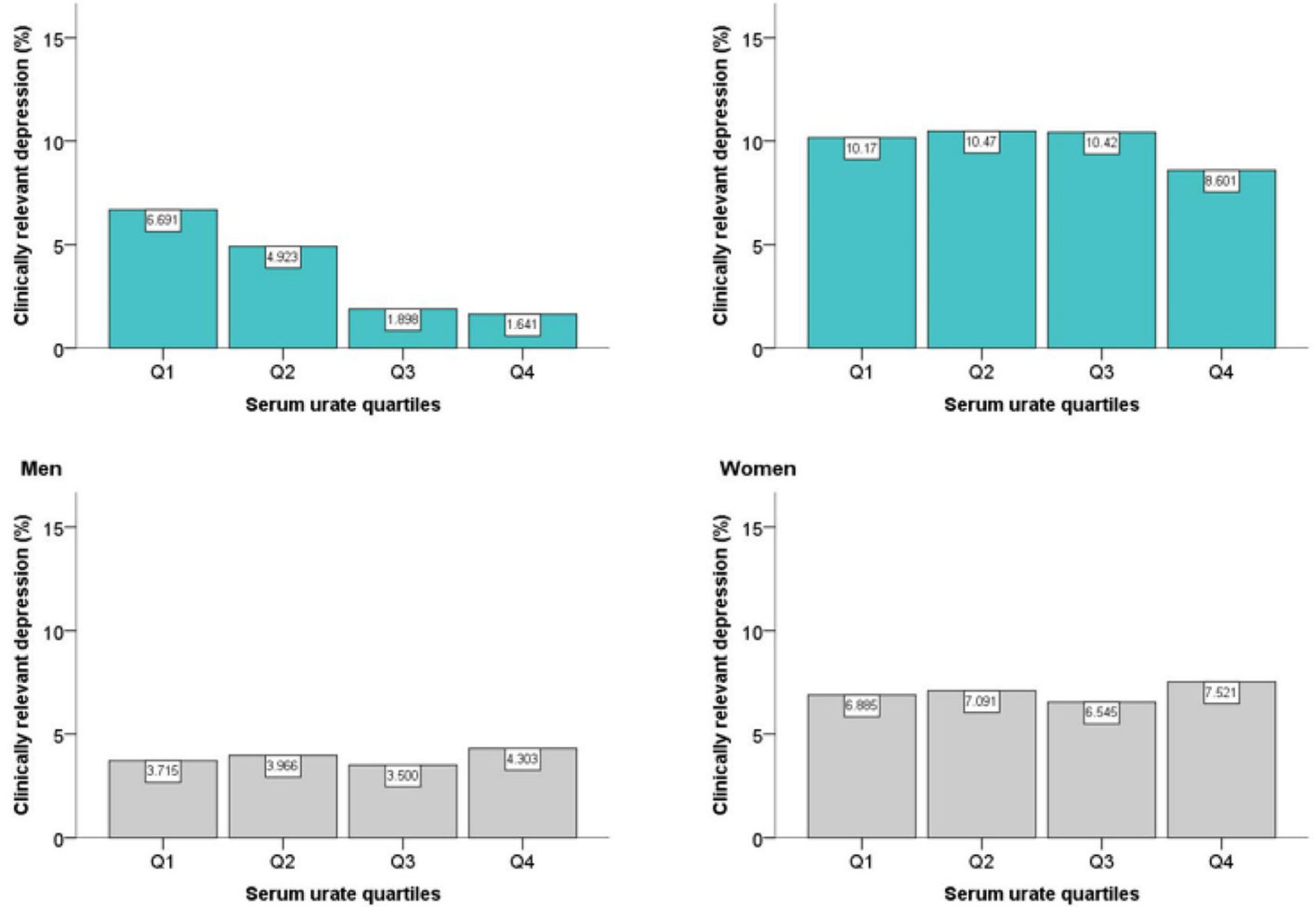

Fig. 3 Prevalence of clinically relevant depression according to serum urate quartiles 
Table 3 Association of serum urate levels with overall depression in older adults

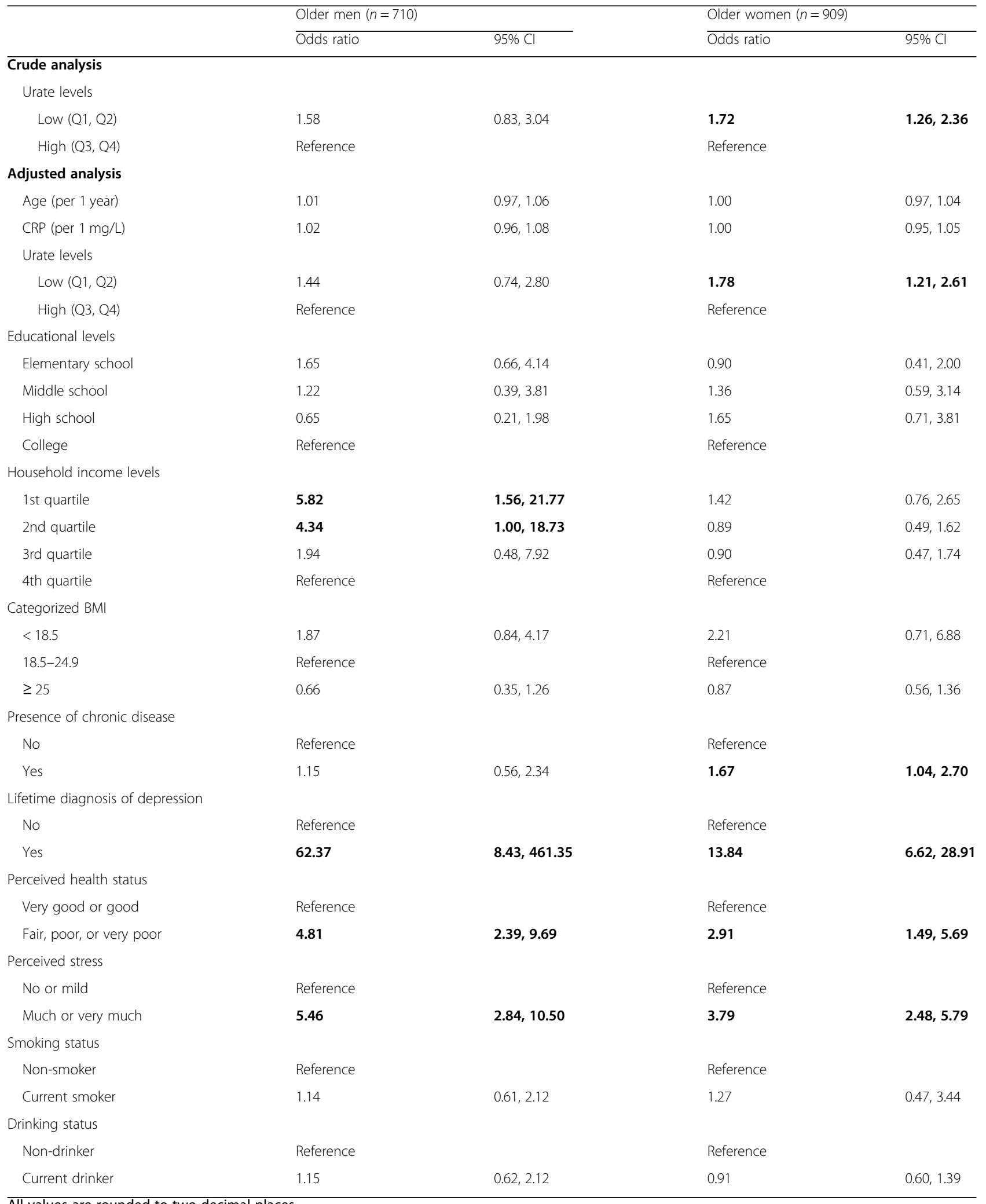

All values are rounded to two decimal places

Bold values denote statistical significance

$B M I$ body mass index, $\mathrm{Cl}$ confidence interval, CRP C-reactive protein 
Table 4 Association of serum urate levels with clinically relevant depression in older adults

\begin{tabular}{|c|c|c|c|c|}
\hline & \multicolumn{2}{|c|}{ Older men $(n=710)$} & \multicolumn{2}{|c|}{ Older women $(n=909)$} \\
\hline & Odds ratio & $95 \% \mathrm{Cl}$ & Odds ratio & $95 \% \mathrm{Cl}$ \\
\hline \multicolumn{5}{|l|}{ Crude analysis } \\
\hline \multicolumn{5}{|l|}{ Urate levels } \\
\hline Low (Q1, Q2) & 3.47 & $1.34,8.96$ & 1.10 & $0.69,1.76$ \\
\hline High (Q3, Q4) & Reference & & Reference & \\
\hline \multicolumn{5}{|l|}{ Adjusted analysis } \\
\hline Age (per 1 year) & 1.01 & $0.93,1.08$ & 1.01 & $0.96,1.07$ \\
\hline CRP (per $1 \mathrm{mg} / \mathrm{L}$ ) & 1.03 & $0.94,1.12$ & 0.98 & $0.90,1.06$ \\
\hline \multicolumn{5}{|l|}{ Urate levels } \\
\hline Low (Q1, Q2) & 3.35 & $1.16,9.70$ & 1.15 & $0.67,1.98$ \\
\hline High (Q3, Q4) & Reference & & Reference & \\
\hline \multicolumn{5}{|l|}{ Educational levels } \\
\hline Elementary school & 0.96 & $0.19,4.79$ & 2.41 & $0.32,17.99$ \\
\hline Middle school & 0.64 & $0.12,3.32$ & 2.66 & $0.29,24.74$ \\
\hline High school & 0.32 & $0.05,2.21$ & 3.12 & $0.32,30.56$ \\
\hline College & Reference & & Reference & \\
\hline \multicolumn{5}{|l|}{ Household income levels } \\
\hline 1st quartile & $-{ }^{\mathrm{a}}$ & & $-{ }^{\mathrm{a}}$ & \\
\hline 2nd quartile & $-{ }^{\mathrm{a}}$ & & $-{ }^{\mathrm{a}}$ & \\
\hline 3rd quartile & $-{ }^{\mathrm{a}}$ & & $-{ }^{\mathrm{a}}$ & \\
\hline 4th quartile & Reference & & Reference & \\
\hline \multicolumn{5}{|l|}{ Categorized BMI } \\
\hline$<18.5$ & 0.83 & $0.20,1.25$ & 0.87 & $0.13,5.84$ \\
\hline $18.5-24.9$ & Reference & & Reference & \\
\hline$\geq 25$ & 0.45 & $0.16,1.25$ & 1.11 & $0.66,1.87$ \\
\hline \multicolumn{5}{|l|}{ Presence of chronic disease } \\
\hline No & Reference & & Reference & \\
\hline Yes & 3.34 & $0.87,12.79$ & 2.92 & $1.31,6.53$ \\
\hline \multicolumn{5}{|c|}{ Lifetime diagnosis of depression } \\
\hline No & Reference & & Reference & \\
\hline Yes & 1.15 & $0.23,5.64$ & 5.14 & $2.58,10.26$ \\
\hline \multicolumn{5}{|l|}{ Perceived health status } \\
\hline Very good or good & Reference & & Reference & \\
\hline Fair, poor, or very poor & 13.42 & $1.60,112.24$ & 11.90 & $2.12,66.84$ \\
\hline \multicolumn{5}{|l|}{ Perceived stress } \\
\hline No or mild & Reference & & Reference & \\
\hline Much or very much & 8.67 & $3.72,20.21$ & 5.91 & $3.26,10.73$ \\
\hline \multicolumn{5}{|l|}{ Smoking status } \\
\hline Non-smoker & Reference & & Reference & \\
\hline Current smoker & 1.17 & $0.45,3.06$ & 3.91 & $1.23,12.49$ \\
\hline \multicolumn{5}{|l|}{ Drinking status } \\
\hline Non-drinker & Reference & & Reference & \\
\hline Current drinker & 1.69 & $0.64,4.46$ & 0.57 & $0.33,0.99$ \\
\hline
\end{tabular}

All values are rounded to two decimal places

Bold values denote statistical significance

$B M I$ body mass index, $\mathrm{Cl}$ confidence interval, $C R P$ C-reactive protein

${ }^{a}$ Values are 0 or indefinite, as there were no or a small number of exposed cases and/or control subjects 
urate levels may still considerably affect older men, as low levels of serum urate triple the odds of clinically relevant depression. Therefore, it seems logical that the association between low levels of serum urate and the overall burden of depressive symptoms in our study may underrepresent that in older men.

In line with the prior observations of a U-shaped curve of serum urate concentrations and mortality [43-46], a similar pattern was found for the overall depression prevalence among young adults. In contrast, those with high levels of serum urate were more likely to have clinically relevant depression; however, this was not significant after adjustment for socio-demographic, health-, and diseaserelated variables. More evidence will be required to determine whether depression in young adults is associated with serum urate concentrations. Further, the observation of a higher prevalence of depression in the fourth quartile than in the third quartile may have resulted from the previous finding that patients with gout are likely to experience depressive symptoms $[47,48]$.

Concerns about the possible detrimental effects of urate-lowering therapy have been gradually raised in line with recent increases in demands for the treatment of asymptomatic hyperuricemia and cardiovascular and/or kidney diseases $[49,50]$, as well as gout. Since novel uricosurics, in addition to potent inhibitors of xanthine oxidase, are expected to provide an efficient and reliable means of urate-lowering [51], there is a need for better understanding of the adverse effects due to low levels of serum urate. However, it is worth acknowledging that the implications of this epidemiological study need to be carefully interpreted with regard to low serum urate levels induced by pharmacological interventions, because it can be assumed that most participants from the general population were not receiving urate-lowering therapy in this study. Future high-quality research on the effects of urate-lowering therapy on neurological and mental health will help clarify such issues.

It is also notable that $25 \%$ of male participants and $75 \%$ of female participants in this study population had serum urate concentrations below $5 \mathrm{mg} / \mathrm{dL}$, which has been conveniently used as an initial therapeutic target for the management of gout, but few patients had concentrations below $3 \mathrm{mg} / \mathrm{dL}$. This means that maintaining relatively low levels in the physiological range but not necessarily very low levels of serum urate may be accompanied by undesirable effects. While this study was conducted in the general population and the importance of the effective management of gout cannot be overstated, our findings may support the use of dose reduction of urate-lowering therapy to less stringent targets after stabilization, as advocated by the British Society for Rheumatology and the European League Against Rheumatism $[5,6]$.
As urate is excreted primarily by the kidneys, elevated serum urate concentrations are strongly correlated with impaired renal function (eGFR $<60 \mathrm{~mL} / \mathrm{min} / 1.73 \mathrm{~m}^{2}$ ) [52]. Based on previous research using the KNHANES dataset and provided that the prevalence of depression increased with chronic kidney disease stage 3 or greater $[53,54]$, the exclusion of these subjects $(n=233)$ from this study could suggest that the association between serum urate levels and the prevalence of depression is unlikely to be related to renal function. However, this could potentially cause bias in the generalizability of the results when, for instance, a considerable number of subjects have impaired renal function.

Data from this cross-sectional study provide a single snapshot in time of serum urate levels and depression status and have a limited capacity to examine any causal relationship. Further clinical and experimental studies will be needed to demonstrate the temporal aspects of the relationship between serum urate levels and depression symptomatology and to investigate the potential mechanistic role of serum urate in the natural history of depressive disorders. Although participants taking an antidepressant for major depressive disorder or other indications may have exhibited few depressive symptoms, it was not possible to determine whether PHQ-9 scores are influenced by prior exposure to antidepressants. In addition, most symptom-screening questionnaires including the PHQ-9 were not designed to ascertain diagnostic status and would theoretically be expected to overestimate prevalence [55]. However, these tools have important applications for the assessment of symptom severity, regardless of the diagnostic status, and as screening tools to identify people who may have depression [56]. There is also an interest in the field of bipolar and related disorders, as shown in a meta-analysis reported that subjects with bipolar disorder had higher serum urate concentrations than healthy controls [57]. It is possible that a portion of patients with bipolar disorder experiencing depression was also included in the analysis.

\section{Conclusions}

Our findings suggest that low levels of serum urate are associated with a higher prevalence of depression in older adults. Longitudinal studies are needed to examine the potential effects of serum urate on the trajectory of depression over time. This may have clinical implications for mental health.

\section{Abbreviations}

BMI: Body mass index; Cl: Confidence interval; CRP: C-reactive protein; eGFR: Estimated glomerular filtration rate; KNHANES: Korea National Health and Nutrition Examination Survey; OR: Odds ratio; PHQ: Patient Health Questionnaire; SE: Standard error 


\section{Acknowledgements}

The authors thank the Korea National Health and Nutrition Examination Survey participants and the staff members for their contribution to the dataset.

\section{Authors' contributions}

W-JK, HRK, and STC participated in the conception and design of the study; JSS coordinated the study; W-JK and STC performed the statistical analysis; W-JK wrote the original draft of the manuscript; STC reviewed and revised the manuscript. All authors were responsible for the interpretation of data and approved the final version of the article.

\section{Funding}

This research was supported by a grant from the Basic Science Research Program through the National Research Foundation of Korea funded by the Ministry of Education, Republic of Korea (2018R1D1A1B07049248).

\section{Availability of data and materials}

The dataset used and/or analyzed during the current study is available from the Korea National Health and Nutrition Examination Survey website (https:// knhanes.cdc.go.kr/).

\section{Ethics approval and consent to participate}

All participants provided informed consent before data collection, and the survey was conducted according to the Article 16 of National Health Promotion Act in Korea. The protocol of this study was in accordance with the Declaration of Helsinki and approved by the institutional review board of the Chung-Ang University Hospital (1908-004-16275).

\section{Consent for publication}

Not applicable.

\section{Competing interests}

The authors declare that there is no conflict of interest.

\section{Author details}

'Division of Rheumatology, Department of Internal Medicine, Chung-Ang University College of Medicine, 102, Heukseok-ro, Dongjak-gu, Seoul 06973, Republic of Korea. ${ }^{2}$ Department of Psychiatry, Chung-Ang University College of Medicine, Seoul, Republic of Korea.

\section{Received: 16 September 2019 Accepted: 22 April 2020}

Published online: 06 May 2020

\section{References}

1. Johnson RJ, Bakris GL, Borghi C, Chonchol MB, Feldman D, Lanaspa MA, Merriman TR, Moe OW, Mount DB, Sanchez Lozada LG, et al. Hyperuricemia, acute and chronic kidney disease, hypertension, and cardiovascular disease: report of a scientific workshop organized by the National Kidney Foundation. Am J Kidney Dis. 2018;71(6):851-65.

2. Perez-Ruiz F, Moreno-Lledo A, Urionaguena I, Dickson AJ. Treat to target in gout. Rheumatology (Oxford). 2018;57(suppl_1):i20-6.

3. Khanna D, Fitzgerald JD, Khanna PP, Bae S, Singh MK, Neogi T, Pillinger MH, Merill J, Lee S, Prakash S, et al. 2012 American College of Rheumatology guidelines for management of gout. Part 1: systematic nonpharmacologic and pharmacologic therapeutic approaches to hyperuricemia. Arthritis Care Res (Hoboken). 2012;64(10):1431-46.

4. Kiltz U, Smolen J, Bardin T, Cohen Solal A, Dalbeth N, Doherty M, Engel B, Flader C, Kay J, Matsuoka M, et al. Treat-to-target (T2T) recommendations for gout. Ann Rheum Dis. 2017;76(4):632-8.

5. Hui M, Carr A, Cameron S, Davenport G, Doherty M, Forrester H, Jenkins W, Jordan KM, Mallen CD, McDonald TM, et al. The British Society for Rheumatology guideline for the management of gout. Rheumatology (Oxford). 2017;56(7):e1-e20

6. Richette P, Doherty M, Pascual E, Barskova V, Becce F, Castaneda-Sanabria J, Coyfish M, Guillo S, Jansen TL, Janssens H, et al. 2016 updated EULAR evidence-based recommendations for the management of gout. Ann Rheum Dis. 2017;76(1):29-42.

7. Yu KH, Chen DY, Chen JH, Chen SY, Chen SM, Cheng TT, Hsieh SC, Hsieh TY, Hsu PF, Kuo CF, et al. Management of gout and hyperuricemia: multidisciplinary consensus in Taiwan. Int J Rheum Dis. 2018;21(4):772-87.
8. Perez-Gomez MV, Bartsch LA, Castillo-Rodriguez E, Fernandez-Prado R, Kanbay M, Ortiz A. Potential dangers of serum urate-lowering therapy. Am J Med. 2019;132(4):457-67.

9. Ames BN, Cathcart R, Schwiers E, Hochstein P. Uric acid provides an antioxidant defense in humans against oxidant- and radical-caused aging and cancer: a hypothesis. Proc Natl Acad Sci U S A. 1981;78(11):6858-62.

10. Kratzer JT, Lanaspa MA, Murphy MN, Cicerchi C, Graves CL, Tipton PA, Ortlund EA, Johnson RJ, Gaucher EA. Evolutionary history and metabolic insights of ancient mammalian uricases. Proc Natl Acad Sci U S A. 2014; 111(10):3763-8.

11. Waring WS, Webb DJ, Maxwell SR. Systemic uric acid administration increases serum antioxidant capacity in healthy volunteers. J Cardiovasc Pharmacol. 2001;38(3):365-71.

12. Amaro S, Laredo C, Renu A, Llull L, Rudilosso S, Obach V, Urra X, Planas AM, Chamorro A, Investigators U-I. Uric acid therapy prevents early ischemic stroke progression: a tertiary analysis of the URICO-ICTUS trial (efficacy study of combined treatment with uric acid and r-tPA in acute ischemic stroke). Stroke. 2016;47(11):2874-6.

13. Justicia C, Salas-Perdomo A, Perez-de-Puig I, Deddens LH, van Tilborg GAF, Castellvi C, Dijkhuizen RM, Chamorro A, Planas AM. Uric acid is protective after cerebral ischemia/reperfusion in hyperglycemic mice. Transl Stroke Res. 2017;8(3):294-305

14. Schwarzschild MA, Macklin EA, Bakshi R, Battacharyya S, Logan R, Espay AJ, Hung AY, Bwala G, Goetz CG, Russell DS, et al. Sex differences by design and outcome in the safety of urate elevation in PD (SURE-PD) trial. Neurology. 2019;93(14):e1328-38.

15. Auinger $P$, Kieburtz $K$, McDermott MP. The relationship between uric acid levels and Huntington's disease progression. Mov Disord. 2010;25(2):224-8.

16. Abraham A, Drory VE. Influence of serum uric acid levels on prognosis and survival in amyotrophic lateral sclerosis: a meta-analysis. J Neurol. 2014; 261(6):1133-8.

17. Euser SM, Hofman A, Westendorp RG, Breteler MM. Serum uric acid and cognitive function and dementia. Brain. 2009;132(Pt 2):377-82.

18. Kim SY, Guevara JP, Kim KM, Choi HK, Heitjan DF, Albert DA. Hyperuricemia and risk of stroke: a systematic review and meta-analysis. Arthritis Rheum. 2009;61(7):885-92.

19. Latourte A, Soumare A, Bardin T, Perez-Ruiz F, Debette S, Richette P. Uric acid and incident dementia over 12 years of follow-up: a population-based cohort study. Ann Rheum Dis. 2018;77(3):328-35.

20. Singh JA, Cleveland JD. Gout and the risk of Parkinson's disease in older adults: a study of U.S. Medicare data. BMC Neurol. 2019;19(1):4.

21. Jimenez-Fernandez $S$, Gurpegui M, Diaz-Atienza F, Perez-Costillas $L$, Gerstenberg M, Correll CU. Oxidative stress and antioxidant parameters in patients with major depressive disorder compared to healthy controls before and after antidepressant treatment: results from a meta-analysis. J Clin Psychiatry. 2015;76(12):1658-67.

22. Wium-Andersen MK, Kobylecki CJ, Afzal S, Nordestgaard BG. Association between the antioxidant uric acid and depression and antidepressant medication use in 96989 individuals. Acta Psychiatr Scand. 2017;136(4):424-33.

23. Bartoli F, Trotta G, Crocamo C, Malerba MR, Clerici M, Carra G. Antioxidant uric acid in treated and untreated subjects with major depressive disorder: a meta-analysis and meta-regression. Eur Arch Psychiatry Clin Neurosci. 2018; 268(2):119-27.

24. Bartoli F, Crocamo C, Bava M, Castagna G, Di Brita C, Riboldi I, Trotta G, Verrengia E, Clerici M, Carra G. Testing the association of serum uric acid levels with behavioral and clinical characteristics in subjects with major affective disorders: a cross-sectional study. Psychiatry Res. 2018;269:118-23.

25. Ferrari AJ, Charlson FJ, Norman RE, Patten SB, Freedman G, Murray CJ, Vos T, Whiteford HA. Burden of depressive disorders by country, sex, age, and year: findings from the global burden of disease study 2010. PLoS Med. 2013;10(11):e1001547.

26. Levey AS, Stevens LA, Schmid CH, Zhang YL, Castro AF 3rd, Feldman HI, Kusek JW, Eggers P, Van Lente F, Greene T, et al. A new equation to estimate glomerular filtration rate. Ann Intern Med. 2009;150(9):604-12.

27. Seo MH, Lee WY, Kim SS, Kang JH, Kang JH, Kim KK, Kim BY, Kim YH, Kim WJ, Kim EM, et al. 2018 Korean Society for the Study of Obesity Guideline for the Management of Obesity in Korea. J Obes Metab Syndr. 2019;28(1):40-5.

28. Kroenke K, Spitzer RL, Williams JB. The PHQ-9: validity of a brief depression severity measure. J Gen Intern Med. 2001;16(9):606-13.

29. Martin A, Rief W, Klaiberg A, Braehler E. Validity of the Brief Patient Health Questionnaire Mood Scale (PHQ-9) in the general population. Gen Hosp Psychiatry. 2006;28(1):71-7. 
30. Chen TM, Huang FY, Chang C, Chung H. Using the PHQ-9 for depression screening and treatment monitoring for Chinese Americans in primary care. Psychiatr Serv. 2006;57(7):976-81.

31. Carballeira Y, Dumont P, Borgacci S, Rentsch D, de Tonnac N, Archinard M, Andreoli A. Criterion validity of the French version of Patient Health Questionnaire (PHQ) in a hospital department of internal medicine. Psychol Psychother. 2007;80(Pt 1):69-77.

32. AlHadi AN, AlAteeq DA, Al-Sharif E, Bawazeer HM, Alanazi H, AIShomrani AT, Shuqdar RM, AlOwaybil R. An Arabic translation, reliability, and validation of Patient Health Questionnaire in a Saudi sample. Ann General Psychiatry. 2017; 16:32.

33. Levis B, Benedetti A, Thombs BD, Collaboration DESD. Accuracy of Patient Health Questionnaire-9 (PHQ-9) for screening to detect major depression: individual participant data meta-analysis. BMJ. 2019;365:11476.

34. Han C, Jo SA, Kwak JH, Pae CU, Steffens D, Jo I, Park MH. Validation of the Patient Health Questionnaire-9 Korean version in the elderly population: the Ansan Geriatric study. Compr Psychiatry. 2008;49(2):218-23.

35. Rodda J, Walker Z, Carter J. Depression in older adults. BMJ. 2011;343:d5219.

36. Barry LC, Abou JJ, Simen AA, Gill TM. Under-treatment of depression in older persons. J Affect Disord. 2012;136(3):789-96.

37. Alexopoulos GS. Mechanisms and treatment of late-life depression. Transl Psychiatry. 2019;9(1):188.

38. Diniz BS, Reynolds CF 3rd, Sibille E, Lin CW, Tseng G, Lotrich F, Aizenstein $\mathrm{HJ}$, Butters MA. Enhanced molecular aging in late-life depression: the senescent-associated secretory phenotype. Am J Geriatr Psychiatry. 2017; 25(1):64-72.

39. Siu AL, Force USPST, Bibbins-Domingo K, Grossman DC, Baumann LC, Davidson KW, Ebell M, Garcia FA, Gillman M, Herzstein J, et al. Screening for depression in adults: US Preventive Services Task Force recommendation statement. JAMA. 2016:315(4):380-7.

40. Maxwell SR, Thomason H, Sandler D, Leguen C, Baxter MA, Thorpe GH, Jones AF, Barnett AH. Antioxidant status in patients with uncomplicated insulin-dependent and non-insulin-dependent diabetes mellitus. Eur J Clin Investig. 1997;27(6):484-90.

41. van Agtmaal MJM, Houben A, Pouwer F, Stehouwer CDA, Schram MT. Association of microvascular dysfunction with late-life depression: a systematic review and meta-analysis. JAMA Psychiatry. 2017;74(7):729-39.

42. Diniz BS, Mendes-Silva AP, Silva LB, Bertola L, Vieira MC, Ferreira JD, Nicolau $M$, Bristot $G$, da Rosa ED, Teixeira AL, et al. Oxidative stress markers imbalance in late-life depression. J Psychiatr Res. 2018;102:29-33.

43. Kuo CF, See LC, Yu KH, Chou IJ, Chiou MJ, Luo SF. Significance of serum uric acid levels on the risk of all-cause and cardiovascular mortality. Rheumatology (Oxford). 2013;52(1):127-34.

44. Odden MC, Amadu AR, Smit E, Lo L, Peralta CA. Uric acid levels, kidney function, and cardiovascular mortality in US adults: National Health and Nutrition Examination Survey (NHANES) 1988-1994 and 1999-2002. Am J Kidney Dis. 2014:64(4):550-7.

45. Tseng WC, Chen YT, Ou SM, Shih CJ, Tarng DC, Taiwan Geriatric Kidney Disease Research G. U-shaped association between serum uric acid levels with cardiovascular and all-cause mortality in the elderly: the role of malnourishment. J Am Heart Assoc. 2018;7(4).

46. Cho SK, Chang Y, Kim I, Ryu S. U-shaped association between serum uric acid level and risk of mortality: a cohort study. Arthritis Rheumatol. 2018; 70(7):1122-32

47. Kuo CF, Grainge MJ, Mallen C, Zhang W, Doherty M. Comorbidities in patients with gout prior to and following diagnosis: case-control study. Ann Rheum Dis. 2016;75(1):210-7.

48. Prior JA, Mallen CD, Chandratre P, Muller S, Richardson J, Roddy E. Gout characteristics associate with depression, but not anxiety, in primary care: baseline findings from a prospective cohort study. Joint Bone Spine. 2016; 83(5):553-8.

49. Stamp L, Dalbeth N. Urate-lowering therapy for asymptomatic hyperuricaemia: a need for caution. Semin Arthritis Rheum. 2017;46(4):45764.

50. Richette $P$, Latourte A, Bardin T. Cardiac and renal protective effects of urate-lowering therapy. Rheumatology (Oxford). 2018;57(suppl_1):i47-50.

51. Bardin T, Richette P. Novel uricosurics. Rheumatology (Oxford). 2018; 57(suppl_1):i42-6.

52. Cirillo M, Laurenzi M, Mancini M, Zanchetti A, Lombardi C, De Santo NG. Low glomerular filtration in the population: prevalence, associated disorders, and awareness. Kidney Int. 2006;70(4):800-6.
53. Kim JW, Moon SJ, Kim HJ, Lee DG. Relationship between chronic kidney disease and depression in elderly Koreans using the 2013 Korea National Health and Nutrition Examination Survey Data. Korean J Fam Med. 2017; 38(3):156-62.

54. Jhee JH, Lee E, Cha MU, Lee M, Kim H, Park S, Yun HR, Jung SY, Kee YK, Yoon CY, et al. Prevalence of depression and suicidal ideation increases proportionally with renal function decline, beginning from early stages of chronic kidney disease. Medicine (Baltimore). 2017;96(44):e8476.

55. Thombs BD, Kwakkenbos L, Levis AW, Benedetti A. Addressing overestimation of the prevalence of depression based on self-report screening questionnaires. CMAJ. 2018;190(2):E44-9.

56. Levis B, Yan XW, He C, Sun Y, Benedetti A, Thombs BD. Comparison of depression prevalence estimates in meta-analyses based on screening tools and rating scales versus diagnostic interviews: a meta-research review. BMC Med. 2019;17(1):65.

57. Bartoli F, Crocamo C, Mazza MG, Clerici M, Carra G. Uric acid levels in subjects with bipolar disorder: a comparative meta-analysis. J Psychiatr Res. 2016;81:133-9.

\section{Publisher's Note}

Springer Nature remains neutral with regard to jurisdictional claims in published maps and institutional affiliations.
Ready to submit your research? Choose BMC and benefit from:

- fast, convenient online submission

- thorough peer review by experienced researchers in your field

- rapid publication on acceptance

- support for research data, including large and complex data types

- gold Open Access which fosters wider collaboration and increased citations

- maximum visibility for your research: over $100 \mathrm{M}$ website views per year

At $\mathrm{BMC}$, research is always in progress.

Learn more biomedcentral.com/submissions 